\title{
Sustainable Development for Food Waste: A Case Study of Catered Meal Service at Schools and Elderly Care Homes
}

\author{
Henrik Barth \\ Halmstad University \\ Emma Bäckman \\ Halmstad University \\ Josefin Ellmarker \\ Halmstad University
}

Food waste is an important topic in the context of sustainable development. Although many studies have addressed this topic, there is still limited knowledge owing to insufficient data. This study reports on food waste in two institutional settings in a Swedish municipality: schools and elderly care homes. The findings suggest it is easier to measure and reduce food waste in stable environments, such as exist at schools, than at environments characterized by change and unpredictability, such as exist at elderly care homes. Specific areas examined and compared include cooking and receiving kitchens, infrastructure, communications, and support.

\section{INTRODUCTION}

About one-third of the world's food is wasted each year. One response to this grave situation is the list of Sustainable Development Goals issued by the United Nations that calls for a significant reduction in global food waste by 2030 (UN, 2016). Goal 12, "Responsible Consumption and Production", calls for a 50\% reduction in food waste at the retail and consumer levels and in the production and post-harvest stages (see also Borzan, 2017). Food production uses many (often scarce, usually costly) resources such as water, land, and energy. If much of that food is not consumed, an enormous amount of resources is wasted. Such food waste has important implications for global and environmental security. Greenhouse gas emissions and depletion of the ground water are only two of the high environmental costs of producing food for human consumption. When much of that food is not consumed, there are economic, environmental, and social costs (Livsmedelsverket, 2017).

The literature on food waste distinguishes between edible food and non-edible food and between recoverable and non-recoverable food (Kantor et al., 1997). Recoverable food includes surplus food from restaurants, grocery stores, and cafeterias. Non-recoverable food includes animal bones, shells, and skin as well as uneaten food prepared/served by food services (i.e., catering companies) that supply 
institutions. Food waste and food loss occur at almost every stage in the food chain (Garnett, 2011; Parfitt et al., 2010).

According to Eriksson et al. (2017), there are two main ways to reduce food waste. First, food waste can be reduced using production flows that address actual needs. This process is referred to as "source reduction". Second, if more food is produced than needed, the excess food should be handled in sustainable ways.

Various researchers have analysed food loss/waste in the food service sector (Boschini et al., 2018; Derqui and Fernandez, 2017; Engström and Carlsson-Kanyama, 2004). Betz et al. (2015) list four categories of food loss/waste in this sector: storage losses, preparation losses, serving losses, and plate waste. Inadequate or faulty storage facilities cause storage losses. Preparation losses, such as vegetable peels and spoiled food, occur during food preparation. Serving losses refer to the unconsumed food left in serving containers, for example, uneaten food at buffet tables. Buzby and Guthrie $(2002$, p. 37) define plate waste "as the proportion of food served that is uneaten, the amount of calories uneaten, or the amount of nutrients uneaten". Plate waste is the largest source of food waste in the food service industry (Engström and Carlsson-Kanyama, 2004).

In a study on greenhouse gases in the food chain, Garnett (2011) charges that agriculture (the first stage in the food chain) is responsible for the largest amount of greenhouse gas emissions. However, food waste, which is also responsible for greenhouse gas emissions, occurs in later stages of the food chain. Betz et al. (2015, p. 225) state:

Food which is wasted in the later stages of the value-added chain has a greater negative effect than food which is wasted in the agricultural stage because additional resources (e.g., kitchen employees, transport and packaging) have been employed to prepare the food stuff for consumption. This is one main reason why the reduction of food waste at the end of the value-added chain (including the food service industry) is of major importance.

The stages in which food waste occurs in the food chain differ from country to country. According to Parfitt et al. (2010), food waste in developing countries occurs primarily in the post-harvest stages whereas food waste in developed countries occurs primarily in the consumer and post-consumer stages. Godfray et al. (2010) reach a similar conclusion. They find that food waste occurs at farms and in transport in developing countries whereas food waste occurs in the last stage of the food chain in developed countries. Reducing food waste at the end of the food chain (the consumer and post-consumer stage) is especially challenging because human behaviour and attitude are causative factors.

Much food waste occurs in institutional settings where food service caterers prepare meals. Some of this waste is attributable to the requirement to serve nutritious food that is not always popular with consumers. Students in schools and the elderly in assisted living residences are often critical of the food chosen by the providers (Goggins and Rau, 2016). However, these menus are planned to ensure good nutrition appropriate for the young or for the elderly. The National School Lunch Program in the United States is an example of how food assistance is provided (Bycker et al., 2014). In this programme, which is a federally funded, low-cost or free lunch programme, the kitchen employees use computer software to determine the required nutritional needs for the different age groups.

The world's population is increasing, arable land is decreasing, and climate change is already affecting food quality and quantity. For these reasons, researchers, scientists, and policy makers are searching for sustainable ways to achieve worldwide food security. Beretta et al. (2013, p. 764) reflect this thinking in their call for efficient and sustainable use of food resources:

Food loss over the entire food value chain represents a significant loss of resources invested in food production, transport, and storage. Since resources (land, energy, fresh water, agricultural in-puts) are limited in nature, they should be applied efficiently and sustainably. 
In their study of plate waste in elementary schools, Getlinger et al. (1996) show that less food is wasted if students have recess before lunch. Buzby and Guthrie (2002) reach a similar conclusion. One explanation is that elementary school children do not finish their lunches because they are eager to return to the playground. A proposal for avoiding food waste in schools, therefore, is to schedule lunch after the morning recess so that lunch is served under less stressful conditions. Getlinger et al. (1996, p. 906) comment on the cost of food waste in schools:

Children often do not consume all the food that is given to them, however. Thus, food that is served and not eaten does not benefit children and represents a cost factor for food service operations.

Other research studies conclude that increasing the awareness of the negative effects of food waste can reduce the amount of food thrown away. For example, in a study of food waste among Italian youths, Principato et al. (2015) found that as young people increase their awareness of these negative effects, they are more likely to change their food habits. They also found that these youths had a better understanding of the economic costs of food waste than they did of the harmful climate effects of food waste.

Mirosa et al. (2016) call attention to the importance of reducing food waste in the food service sector. Their solutions to the problem include the following: reducing food choices, reducing plate size, and preordering meals. They also promote the use of campaigns that raise people's awareness of the negative effects of food waste.

Engelund et al. (2009) studied food waste at large-scale hospital kitchens in Denmark. They found the use of Lean principles in the kitchens improved the efficiency of food preparation, the quality of the food, and the employees' working conditions - all of which reduced food waste. While Lean principles are usually associated with the manufacturing sector, these researchers demonstrated that Lean principles are also applicable in the large-scale food service sector. For example, both sectors use methods that produce a high volume of products according to step-by-step schedules designed to avoid delays in production.

In addition to the use of Lean principles, the large-scale food service sector has adopted new technologies for smart solutions that can customize the work. Godfray et al. (2010) argue that the introduction of these new technologies at different stages in the food supply chain can reduce food waste. According to Parfitt et al. (2010, p. 3079), "Irrespective of global region, there is a need for successful introduction of culture-specific innovations and technologies across the FSC [food supply chain] to reduce losses".

Boschini et al. (2018) conducted an extensive review of food waste in schools. They conclude that although many direct and indirect methods for measuring food waste have been developed, no appropriate methodology has yet been identified for use in large-scale studies on food waste in school canteens. Eriksson et al. (2018) concur that many international studies of food waste lack sufficient empirical data.

Food waste in Sweden is an increasing concern, in particular because of its harmful effect on the environment. Two national food and environmental agencies in Sweden have conducted several studies on the food waste problem. The results are shocking. In 2014, 1.3 million tons of food were wasted in Sweden (Naturvårdsverket, 2016). About 70000 tons of food waste are generated every year in the Swedish public food service sector (Eriksson et al., 2018).

Before proposing solutions to reduce food waste, a better grasp of the magnitude of the problem is needed. This requires greater understanding of how food waste measures are used and evaluated. Therefore, this paper examines how food waste is measured and handled and addresses sustainable actions that can be taken to reduce food waste. The empirical data for this study come from two public institutions in the municipality of Halmstad, Sweden - schools and elderly care homes where large-scale food caterers prepare and serve the meals. 


\section{METHODOLODY}

Food waste can be measured directly by weighing the food waste or estimated indirectly by visual estimations or questionnaires completed by participants (Boschini et al., 2018). The direct methods are usually presented as standards while the visual estimations/questionnaires are proposed as reliable and time-saving alternatives (Hanson et al., 2016). In this study, multiple research methods were used. Empirical qualitative data were collected in study visits at three food kitchens and by a quantitative survey conducted with 50 kitchen employees. A pilot study conducted at large-scale caterers preceded this study.

Three kitchens operated by large-scale food caterers were visited: two kitchens at elderly care homes and one school kitchen. Qualitative data were collected using semi-structured interviews conducted at the three kitchens. An interview guide, prepared prior to these visits, was used in the interviews. The interview questions addressed food preparation, inventory procedures, recycling, and storage. Initially, the production managers at each kitchen were interviewed by a member of the research team. Other members on the team took notes during the interviews. Follow-up questions were also asked. After the interviews, the research team inspected food preparation in the kitchens and discussed procedures related to food preparation with other individuals employed by the catering services.

Two web-based surveys were conducted after the study visits - a survey with 14 kitchen employees at five elderly care homes and a survey with 36 kitchen employees at 18 schools. Permission to conduct the surveys was obtained from various production managers at large-scale food caterers in Halmstad, Sweden. These managers sent the surveys to their employees. All survey responders were assured their responses would be anonymous.

The intention of the surveys was to elicit data on the amount of food waste, the reasons for food waste, and actions taken to reduce food waste. The survey, which were based on the information acquired in the study visits, produced considerable quantitative data.

To support the trustworthiness of the research findings, both qualitative and quantitative research methods were used in this study. A team of researchers conducted the investigation, which meant several team members engaged in open conversations with the study's participants and reviewed and analysed all data collected. The issue of food waste was broadened by studying meal procedures at the school kitchen and at the elderly care home kitchens.

A limitation of the study was that the interviews and discussions were only with the caterers' personnel. Future research on the same issue would benefit from the inclusion of other participants such as teachers, students, and parents at schools, and residents and nurses at elderly care homes.

\section{RESULTS}

The study visits to the three cooking kitchens revealed both similarities and differences in their work procedures and routines, as discussed next.

Each of the three food service caterers in this research employs a production manager who has overall responsibility for the kitchens. This responsibility includes the purchase of food and small kitchen tools. The Halmstad municipality is responsible for the purchase of large equipment and the supervision of construction projects for new kitchens.

Administrators and politicians in the Halmstad municipality take a supervisory role in the procedures and policies related to institutional food service catering. In 2012/2013, for example, they decided that the large-scale caterers for the schools and the elderly care homes should provide two different main dishes daily. Although this decision meant greater meal choice, it also meant more work for kitchen employees and possibly more food waste (see Mirosa et al., 2016, on how fewer meal choices help reduce food waste).

In addition, the municipal organization, Måltidsservice ["Meal Service", in English], which consists of a group of about 280 people, actively participates in nine areas related to meal menus and food preparation for pre-schools, elementary and high schools, and elderly care homes. They also provide 
Meals on Wheels. The organization encourages the use of locally grown ecological ingredients, a reduction in food waste, and a decrease in the consumption of meat. In preparing menus, their aim is to provide advice and inspiration to the caterers that prepare the meals. Production managers can change these menus depending on individual conditions as long as they maintain the same nutritional standards.

In recent years, several actions in the large-scale food service sector have improved the efficiency of food production at elderly care homes and at schools. Although most meals are prepared the same day they are served, kitchen employees increasingly prepare some dishes, or parts of dishes, the day before they are served. The software program, "Matilda," is used to search for new recipes, to find nutritional information, and to help plan and place orders for ingredients. Given the flexibility the kitchen employees have for changing the suggested menus, they can add/delete menu items in order to reduce food waste. They see first-hand which dishes students and the elderly like or dislike.

Måltidsservice, which documents food waste, provides this information to the large-scale catering establishments. This information includes the number and kind of dishes served, and the food waste and plate waste measured in kilograms. The employees at the three kitchens in the study also document the number of people at meals and the amount of food waste and plate waste in kilograms.

The cooking kitchens for the elderly care homes and the school in the study were rather similar as far as layout, equipment, tools, and work procedures and routines. However, the kitchens differed in some respects given the different consumer food preferences, habits, and nutritional needs. Moreover, the students only have lunch at school whereas the elderly care home residents have other meals.

The school requires kitchen employees Monday through Friday only. The elderly care homes require kitchen employees every day of the week. This latter group of employees also prepares food for other elderly care divisions that lack cooking kitchens. The kitchen employees at the school generally do not have this additional responsibility. Thus, it was easier for the school kitchen employees to measure food waste than it was for the elderly care home kitchen employees who lack control over food waste at the other elderly care divisions. This is a particularly problematic situation because these other divisions can change the number of orders as late as the morning of delivery. Because certain dishes are prepared in advance, these late orders meant some food was wasted.

Late orders were usually not a problem for the school kitchen employees because special situations (e.g., school trips) are scheduled in advance. Therefore, the school's kitchen employees should receive timely notice that fewer meals are needed. However, one problem arises near summer school vacation when school schedules are more flexible. At this time, some students choose to eat lunch at home. This situation, which cannot be anticipated with any certainty, often results in food thrown away.

The web-based surveys provided data on how the responders viewed various issues related to food waste in their institutional settings.

Figure 1 presents the responses to the question about the amount of daily food waste at the elderly care homes as measured in kilograms. More than $50 \%$ of the responders indicated that daily food wasted measured between 5 and 10 kilograms. 


\section{FIGURE 1 \\ FOOD WASTE IN KILOGRAMS PER DAY IN ELDERLY CARE}

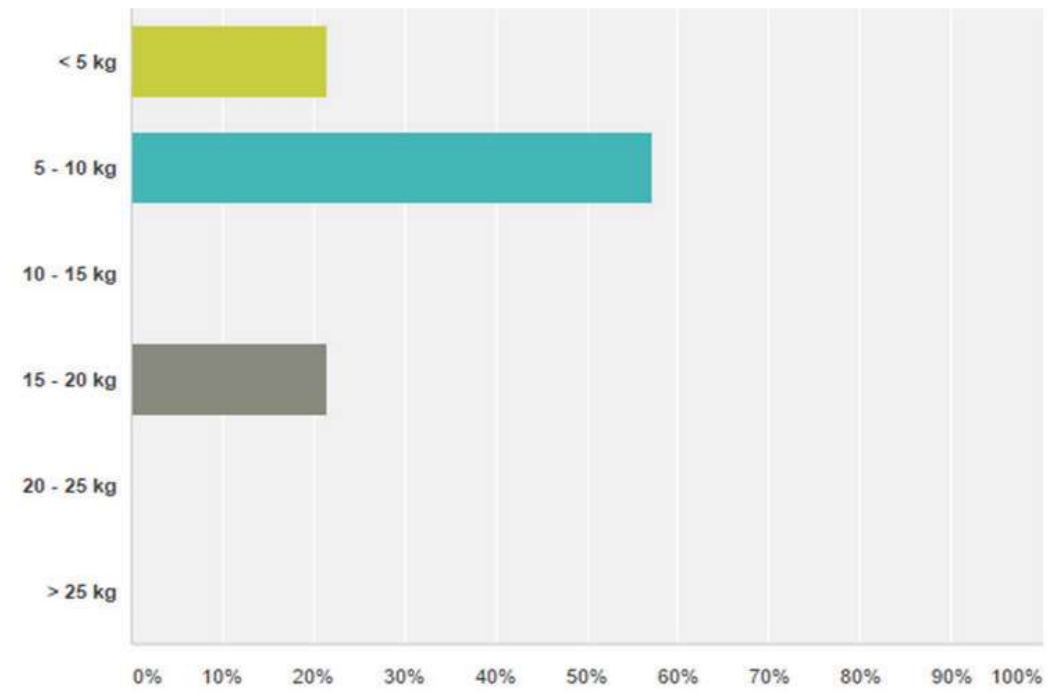

Figure 2 presents the reasons for food waste in the kitchens at the elderly care homes. Of the responders, $43 \%$ chose the option "Too much food is served and must be thrown away". Among the 57\% of responders who chose the option "Other", many explained that they received prepared meals from other elderly care kitchens. A typical response was the following:

Food is returned from the divisions. There are a lot of divisions. It varies day-to-day how much the residents eat. 


\section{FIGURE 2}

\section{FOOD WASTE IN THE KITCHENS IN ELDERLY CARE}

The food gets bad and needs to be thrown

Too much food is served in the restaurant and needs to be thrown

The food is defaulted because of the wrong cooking method

Changes in the order from the customers and therefore food needs to be thrown

Other

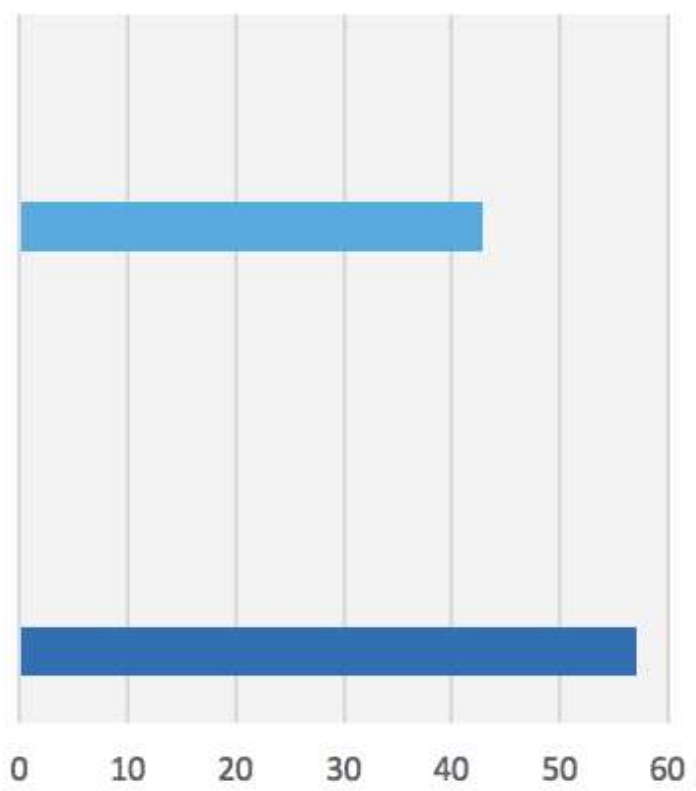

Figure 3 presents the responses to the questions about the reasons for food waste in the elderly care homes in general. Of the responders, $50 \%$ chose the option "When too much food is ordered, the excess must be thrown away". About $43 \%$ of the responders chose the option "Other". Typical explanations for this choice were the following:

I think there is poor communication between the kitchens and the elderly care nurses.

I think that sometimes too much food is served. The extra is thrown out. I don't know how much food is thrown out in the evenings because the divisions handle this themselves. 
FIGURE 3

REASONS FOR FOOD WASTE IN ELDERLY CARE

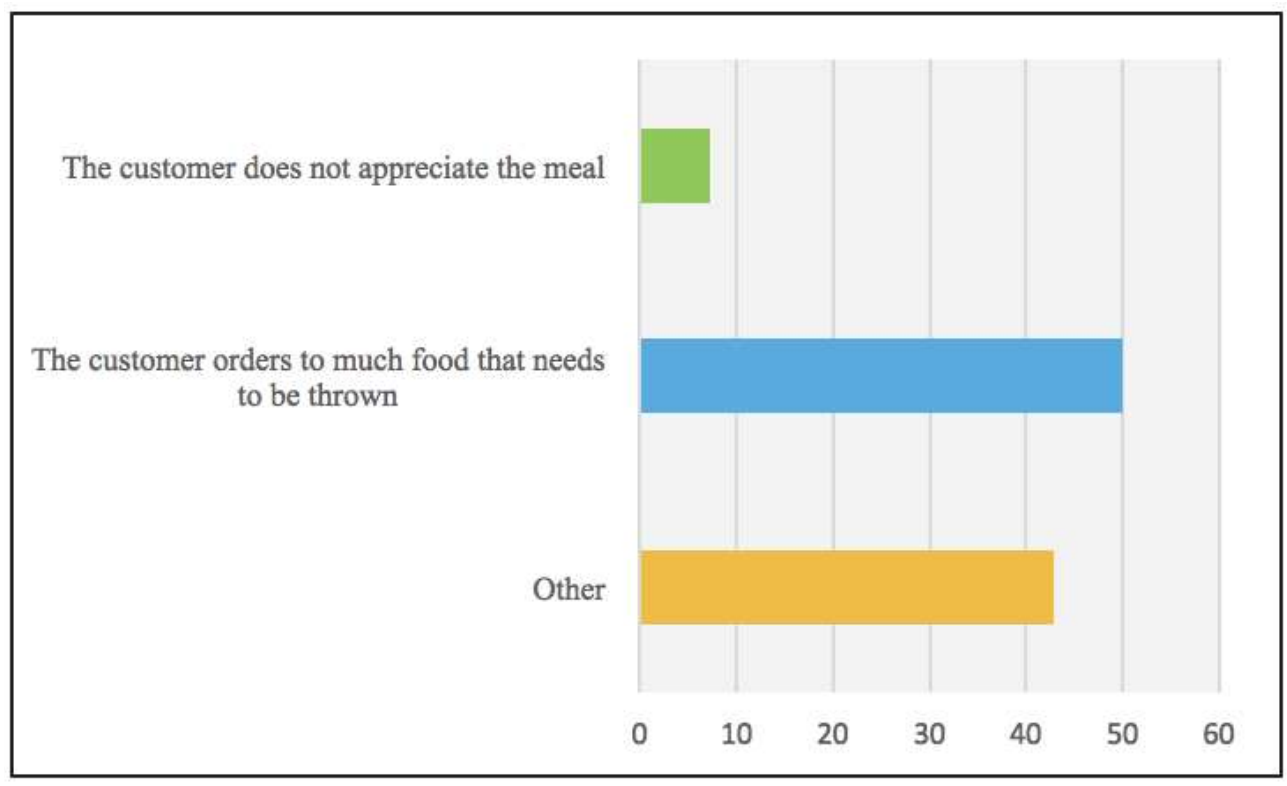

Responders were also asked if they had any suggestions on how to reduce food waste. Many responders commented on the lack of good communications between the kitchens and the nurses for the elderly. They think the nurses often order too much food.

The nurses should be more active. They should tell the kitchen if the residents don't have a good appetite on some days.

More communication with the residents is needed.

The last question in the survey asked how the responders worked with food waste in their kitchens. The responses included the following: reducing portion sizes, changing menus, and freezing/reheating leftover food.

We have a reference list for the portion size. We usually follow this list, but sometimes we change, depending on whether people like some food and whether some eat more. We freeze and reheat the leftover food (stews, etc.). Or we serve it the day after. If we have cooked leftover potatoes, we can fry them the next day.

Figure 4 presents the responses to the question about the amount of daily food waste at the schools as measured in kilograms. The amount of daily food waste at the schools was significantly greater than at the elderly care homes. 
FIGURE 4

FOOD WASTE IN KILOGRAMS PER DAY AT THE SCHOOLS

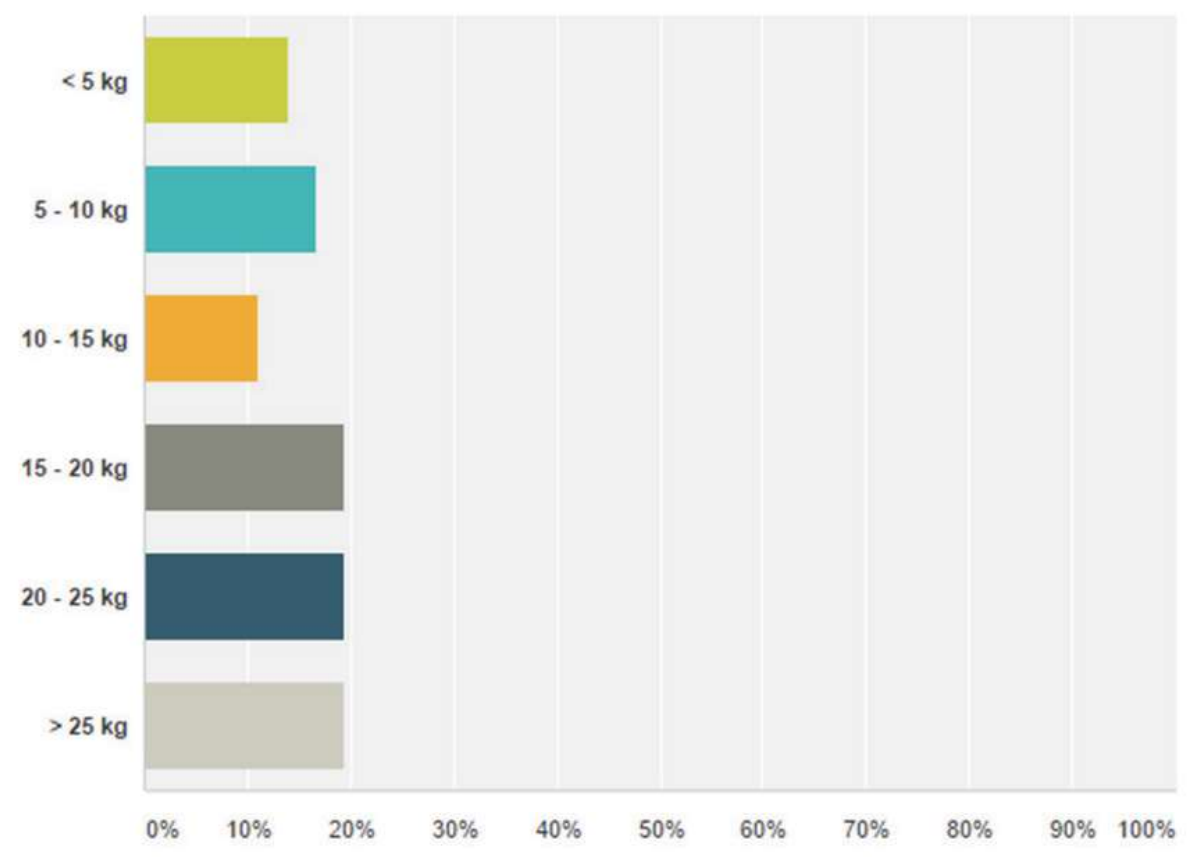

Figure 5 presents the responses to question about the reasons for food waste at the schools. Of the responders, 78\% said the students take too much food because they do not want to go through the line twice. Some responders said the students "do not appreciate the meals". Others said the students are "stressed and therefore take too much food".

These responses are based on the kitchen employees' communications with the students in the cafeteria. By talking to the students, the employees learn the students' food preferences. They use this information to adapt the suggested menus and thus to help reduce food waste. They also try to motivate the students to throw away less food, School campaigns teach students the adverse effects of food waste. Typical responses included the following:

We encourage the children to taste the food before taking a larger portion. We also work with incentives to avoid food waste and have weeks when the children can ask for the food they want for lunch.

For each meal, I write down how much food has been cooked and how much food has been thrown away. When we cook the same meal next time, I check how much was consumed the last time.

We use the food that has been left over in buffets to minimise food waste.

The kitchen employees also said that the students' parents should be informed about food waste and its consequences. Furthermore, they said food waste would be reduced if more teachers had supervisory responsibility in the cafeteria. 
I believe that a better time table could minimise food waste. If each class ate at the same time every day, it would be easier for the kitchen to measure how much each class eats and thus cook the right amount of food. I also believe that lunch should be on the schedule. Teachers should eat lunch with their classes in the cafeteria. An outdoor break should be scheduled after more lessons. I think this schedule would make eating lunch less hurried and less stressful for the students.

\section{FIGURE 5 \\ REASONS FOR FOOD WASTE AT THE SCHOOLS}

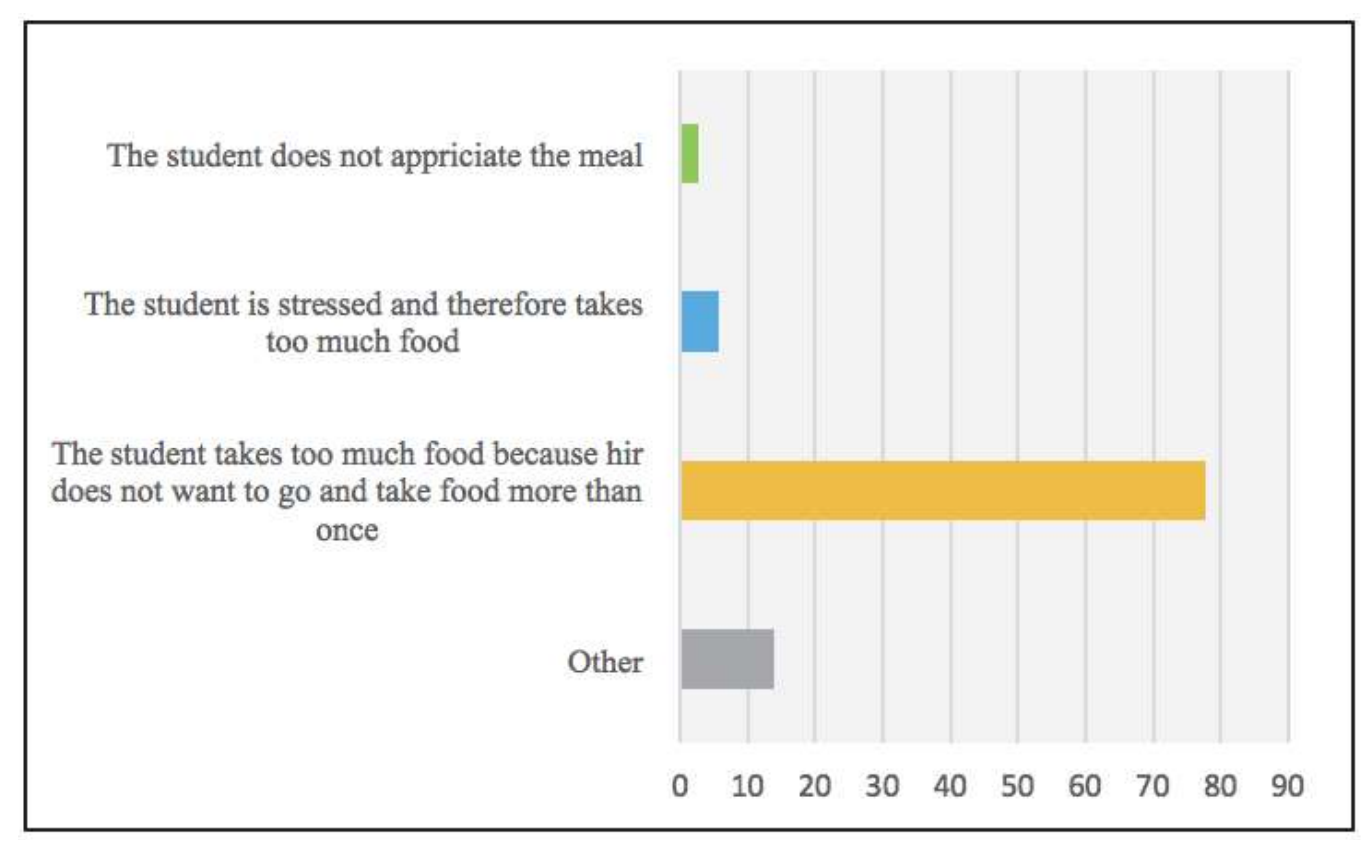

The last questions asked the responders to describe their work with food waste and to propose ideas for reducing food waste. Most responders stressed the importance of greater awareness of the negative effects of food waste, in particular the cost of food thrown away. The responders recommended using leftovers where possible in the preparation of other meals (e.g., leftover sauces in stews). They also suggested that the size of portions should be controlled more closely.

\section{DISCUSSION}

The major type of food waste at the two institutional settings of this study was plate waste. This result confirms findings in other studies in Sweden (Eriksson et al., 2018) and in Italy (Boschini et al., 2018). Engström and Carlsson-Kanyama (2004) found that plate waste accounts for 11-13\% of all wasted food at Swedish institutions where food services provide meals. However, the kitchen employees in this study had little or no control over the amount of plate waste. They were responsible only for food orders and preparation in accordance with food waste advice from the Swedish government:

As a large-scale catering employee, you can minimise the kitchen's and the guests' waste by, for example, planning purchases, cooking the food in sets with opportunities to take care of leftovers, and adapting the portion sizes after the guests' needs and wishes. (Livsmedelsverket, 2017) 
Poor communication was another reason for food waste in these settings. At both the elderly care homes and the schools, kitchen employees needed more information on the number of meals required daily. To the extent practical and feasible, other staff members should inform kitchen employees early in the day as to the number of meals required.

The kitchen employees were aware of the importance of reducing food waste, primarily from an economic point of view. They also thought greater awareness of the food waste problem was needed. In particular, they thought students should be taught that food waste has economic and environmental costs.

The kitchen employees at both the elderly care homes and the schools were aware of food waste and tried to minimise it. It was very challenging for the kitchen employees at the elderly care homes to measure food waste for two reasons. First, they were unable to determine how much food was needed daily because the residents' appetites varied day to day. Second, the number of meals required daily was difficult to calculate because some residents were short-term residents. This situation complicated the ordering. At the schools, food waste was in large part explained by the students' lack of understanding of the importance of food waste. For various reasons, the students tended to take more food than they could eat. The school kitchen employees also have an ordering problem when students eat at home instead of in the cafeteria.

Figures 6 and 7 illustrate the food focus and distribution in the elderly care homes and in the schools. The larger the circle, the greater the focus.

FIGURE 6

THE FOOD FOCUS AND DISTRIBUTION IN ELDERLY CARE

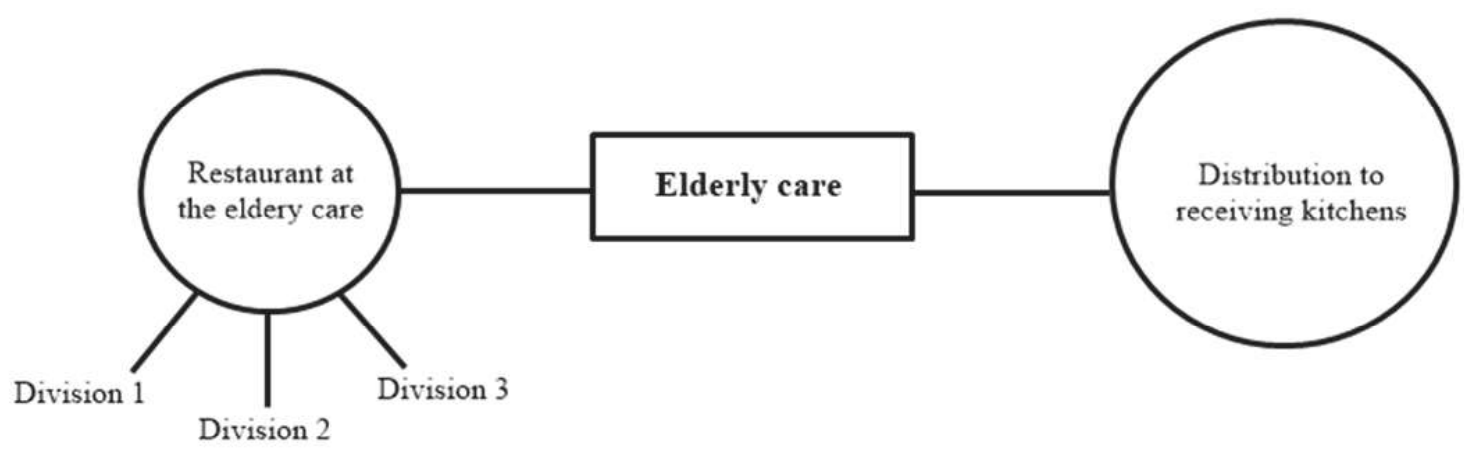

FIGURE 7

THE FOOD FOCUS AND DISTRIBUTION IN THE SCHOOLS

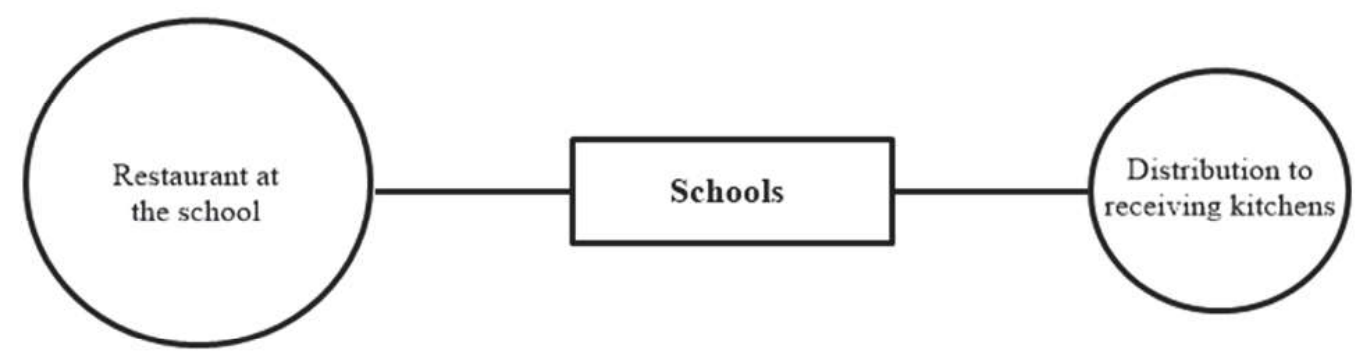

Measuring food waste was a simpler process at the schools than at the elderly care homes. Some elderly care homes have their own dining rooms where meals are served. The kitchens for these homes also send food to other elderly care divisions. The kitchen employees had no information on, or control 
of, the food waste (including plate waste) at these divisions. Moreover, because the divisions' receiving kitchens lack cooling facilities, food waste probably increased.

In their quantitative study on food waste in public catering services, Eriksson et al. (2017) report that receiving kitchens have $42 \%$ more food waste than cooking kitchens. The current study points to problems with communications between cooking and receiving kitchens regarding order changes. In addition, the receiving kitchens may lack chilling space. Simply put, these receiving kitchens lack the infrastructure and support that could help reduce food waste. This is a problem the Halmstad municipality has not yet addressed.

At the schools, all students eat lunch in the cafeteria. With only one dining location, it is easier for the kitchen employees to measure the food waste at the schools. In addition, plate waste can be measured more easily at the schools because students leave their plates at the washing station.

\section{CONCLUSIONS}

Food waste is an important issue in the quest to achieve a more environmentally sustainable world. This study described two institutional settings with variations in the amount of food waste. In general, it is easier to measure food waste and to take corrective action in a setting with a stable environment such as the school setting. At the schools in this study, the daily number of students expected to eat in the cafeteria could reasonably be estimated so that the number of lunches could be planned for. However, in less stable environments such as the elderly care homes in this study, such planning is more challenging. Last-minute changes to orders from receiving kitchens at the elderly care divisions were problematic. In these cases, limited support combined with weak communications and inadequate infrastructure resulted in food waste. Eriksson et al. al (2018) reach a similar conclusion.

It should be mentioned that the kitchen employees in the large-scale food service sector in the Halmstad municipality were increasingly aware of the food waste problem. They tried to reduce food waste when ordering supplies and preparing meals. However, because of certain factors outside their control, their efforts were somewhat ineffective.

The study identifies the main food waste problems at the Halmstad municipality's elderly care homes and schools. The kitchen employees at the elderly care homes lack effective food measurement and control functions when they send cooked meals to the receiving kitchens at the elderly care divisions. They also cannot determine the number of required meals daily if the nurses do not communicate the number of absentees or the lack of residents' appetites. The kitchen employees at the schools cannot determine the number of meals required if they lack information on the number of absentees (e.g., because of illness or field trips). Nor can the kitchen employees at the schools control the amount of food students serve themselves, much of which is uneaten.

This research describes the severity of the food waste problem in two public institutional settings in a Swedish municipality. Clearly, such food waste is a financial cost to the local government. Given the food insecurity in some parts of the world, many people also claim food waste has a moral cost. Additionally, wasted food has many negative environmental implications: overflowing landfills, greenhouse gas emissions, and poor use of limited resources such as land, water, and energy. In the institutional settings that this research explores, more and improved communication is needed between the cooking kitchens and the administrators/nurses who deal with food service caterers. A greater emphasis on the harmful effects of food waste is also needed, particularly among school-age children.

Further research is needed to quantify food waste, especially in more remote institutional settings that lack a kitchen for food preparation. These settings have significant amounts of food waste. Such research should address economic factors as well as social and sustainability factors. 


\section{REFERENCES}

Beretta, C., Stoessel, F., Baier, U., \& Hellweg, S. (2013). Quantifying food losses and the potential for reduction in Switzerland. Waste Management, 33(3), 764-773.

Betz, A., Buchli, J., Göbel, C., \& Müller, C. (2015). Food waste in the Swiss industry-Magnitude and potential for reduction. Waste Management, 35, 218-226.

Borzan, B. (2017). Report on initiative on resource efficiency: reducing food waste. Improving Food Safety (2016/2223(INI)), Committee on the Environment, Public Health and Food Safety, Brussels.

Boschini, M., Falasconi, L., Giordano, C., \& Alboni, F. (2018). Food waste in school canteens: A reference methodology for large scale studies. Journal of Cleaner Production. 182, 1024-1032.

Buzby, J. C., \& Guthrie, J. F. (2002). Several strategies may lower plate waste in school feeding programs. Food Review, 25, 36-42.

Byker, C. J., Farris, A. R., Marcenelle, M., Davis, G. C., \& Serrano, E. L. (2014). Food waste in a school nutrition program after implementation of new lunch program guidelines. Journal of Nutrition Education \& Behavior, 46(5), 406-411.

Derqui, B., \& Fernandez, V. (2017). The opportunity of tracking food waste in school canteens: Guidelines for self assessment. Waste Management, 69, 431-444.

Engelund, E. H., Breum, G., \& Friis, A. (2009). Optimisation of large-scale food production using Lean Manufacturing principles. Journal of Foodservice, 20(1), 4-14.

Engström, R., \& Carlsson-Kanyama, A. (2004). Food losses in food service institutions: examples from Sweden. Food Policy, 29(3), 203-213.

Eriksson, M., Osowski, C. P., Malefors, C., Björkman, J., \& Eriksson, E. (2017). Quantification of food waste in public catering services-A case study from a Swedish municipality. Waste Management, 61, 415-422.

Eriksson, M., Osowski, C. P., Björkman, J., Hansson E., Malefors, C., Eriksson, E., \& Ghosh, R. (2018). The tree structure - A general framework for food waste quantification in Food Services. Resources, Conservation \& Recycling, 130, 140-152.

Garnett, T. (2011). Where are the best opportunities for reducing greenhouse gas emissions in the food system (including the food chain)? Food Policy, 36, S23-S32.

Getlinger, M. J., Laughlin, C. V., Bell, E., Akre, C., \& Arjmandi, B. H. (1996). Food waste is reduced when elementary-school children have recess before lunch. Journal of the American Dietetic Association, 96(9), 906-908.

Godfray, H. C. J., Beddington, J. R., Crute, I. R., Haddad, L., Lawrence, D., Muir, J. F., ... Toulmin, C. (2010). Food security: The challenge of feeding 9 billion people. Science, 327(5967), 812-818.

Goggins, G., Rau, H. (2016). Beyond calorie counting: Assessing the sustainability of food provided for public consumption. Journal of Cleaner Production, 112, 257-266.

Hanson, C., et al. (2016). Food Losses and Waste Accounting and Reporting Standard. https://www.wri.org/sites/ default/files/REP_FLW_Standard.pdf. Viewed 181010.

Kantor, L. S., Lipton, K., Manchester, A., \& Oliveira, V. (1997). Estimating and addressing America's food losses. Food Review, 20(1), 2-12.

Livsmedelsverket (2017). Slutrapport - Regeringsuppdrag för minskat matsvinn 2013-2015. . [pdf] Livsmedelsverket. Retrieved May 31, 2017, from https://www.livsmedelsverket.se/globalassets/matvanor-halsa-miljo/miljo/matsvinn/slutrapportmatsvinn_160321.pdf

Mirosa, M., Munro, H., Mangan-Walker, E., \& Pearson, D. (2016). Reducing waste of food left on plates: Interventions based on means-end chain analysis of customers in foodservice sector. British Food Journal, 118(9), 2326-2343. 
Naturvårdsverket (2016). Matavfall i Sverige - uppkomst och behandling. [pdf] Naturvårdsverket. Retrieved May 31, 2017, from http://www.naturvardsverket.se/Documents/publikationer6400/978-91-620-87654.pdf?pid $=18807$

Parfitt, J., Barthel, M., \& Macnaughton, S. (2010). Food waste within food supply chains: uantification and potential for change to 2050. Philosophical Transactions of the Royal Society B: Biological Science, 365(1554), 3065-3081.

Principato, L., Secondi, L., \& Pratesi, C. A. (2015). Reducing food waste: an investigation on the behaviour of Italian youths. British Food Journal, 117(2), 731-748.

UN (2016). United Nations Sustainable Development Goals. United Nations, New York. Retrieved October 18, 2010, from https://www.un.org/sustainabledevelopment/ 